\title{
Neoimperialismo y neoliberalismo
}

\author{
Fernando Paz Sánchez* \\ La palabra que se usa ahora para implicar todo es globalización. \\ Puede significar todo, puede significar nada. \\ ¿Para ti qué significa globalización? \\ Rolando Cordera ${ }^{1}$
}

\section{Resumen}

El objetivo central de este trabajo es contribuir a la divulgación de un conocimiento más certero y objetivo del fenómeno de internacionalización de la economía, su alcance y sus efectos principales en el proceso de desarrollo económico y social reciente de nuestro país. A pesar de lo mucho que se ha escrito sobre el tema de la globalización resulta muy común, inclusive en el ámbito académico, escuchar diversas interpretaciones sobre este concepto y también se aprecia, como resultado de la mayor difusión y sencillez que tienen las ideas centrales, recurrir a explicaciones basadas en la noción "pop" de la globalización, misma que tiende a oscurecer el fondo desigual y asimétrico en que se llevan a cabo las relaciones económicas, políticas y sociales entre las diferentes naciones del mundo. La globalización en su periodo histórico más reciente, aproximadamente en los últimos veinticinco años, ha estado acompañada y ha sido apoyada por una política económica que las potencias centrales procuran establecer e impulsar en todos los demás países del mundo, sin tomar en cuenta sus diferencias históricas, culturales, políticas, sociales y desde luego económicas. Se busca, en estas notas, dejar en claro que la globalización responde a las necesidades de expansión y dominio de los mercados de los países con mayor grado de desarrollo relativo y que las naciones dependientes enfrentan problemas cada vez más serios para superar el desempleo, la subocupación, la pobreza y la marginación de los sectores más numerosos de su población.

Palabras clave: globalización, neoliberalismo, neoimperialismo, dependencia y subdesarrollo.

\footnotetext{
* Investigador de la División de Investigación de la Facultad de Contaduría y Administración, UNAM. Correo electrónico: ferpasa@yahoo.com

${ }^{1}$ Rolando Cordera, "El futuro de la política", Nexos, volumen XXI, número 251, México, noviembre 1998, Nexos, sociedad, ciencia y literatura, p. 44.
} 


\section{Introducción}

urante los últimos veinte años se ha vuelto lugar común el uso y el abuso del término globalización para fundamentar o bien con el propósito de afirmar el comportamiento de las variables económico-financieras, así como para justificar las decisiones políticas, los gustos y preferencias de los consumidores y los hechos mismos de la vida diaria. No obstante, el conocimiento del término y su verdadero alcance parece no ser muy preciso. Así, por ejemplo, Rolando Cordera en una entrevista con Zaki Laïdi obtuvo esta respuesta del maestro del Instituto de Estudios Políticos de París y autor del libro Un mundo sin sentido: "[...] la globalización se está convirtiendo en una ideología, se está convirtiendo en una teoría del cambio social que está tomando el lugar de las viejas ideologías, como por ejemplo las ideologías de la modernización. Es ya un intento de explicación del mundo, del cambio social, a nivel global [...]". ${ }^{2}$

Por otra parte, también en diversos foros y en las propuestas de los partidos políticos se ha insistido en la necesidad de buscar alternativas al neoliberalismo. Al respecto, Jorge G. Castañeda comentó, en una conversación sostenida con Héctor Aguilar Camín y el propio Rolando Cordera Campos, lo siguiente: "Creo que el enigma y la complicación reside justamente en esta relación de sinónimos que se ha establecido entre globalización y neoliberalismo". ${ }^{3}$

Como puede advertirse en las citas anteriores, inclusive al nivel de conocimiento de personas que cuentan con un alto grado de preparación académica y vasta experiencia en materia docente, existe falta de precisión y consenso sobre el significado y alcance de la globalización y del neoliberalismo. Por lo mismo, con objeto de contribuir a la difusión y al manejo apropiado de estos términos, y muy especialmente con el ánimo de dar a conocer su verdadero alcance en el desarrollo económico y sus implicaciones en el desenvolvimiento actual de nuestro país, se consultaron varios trabajos que abordan esos temas.

El proceso de consulta permitió seleccionar el libro Globalización: crítica a un paradigma, coordinado por John Saxe-Fernández, profesor titular de la Facultad de Ciencias Políticas y Sociales de la Universidad Nacional Autónoma de México,

2 Idem, p. 44.

${ }^{3}$ Héctor Aguilar Camín, Jorge G. Castañeda y Rolando Cordera Campos, "Globalización y neoliberalismo", Nexos, op. cit., p. 41. 
publicación que recoge nueve ensayos acerca de la globalización y el neoliberalismo, ya que a pesar de la amplia difusión que ha tenido la misma merece, por la importancia de su contenido, ser objeto de conocimiento por quienes no han tenido oportunidad de consultarla, así como de análisis y reflexión por las personas ocupadas en el campo de las ciencias sociales. En la lectura y en la discusión de ese libro se encuentran los elementos necesarios para conocer el significado y alcance verdaderos del neoliberalismo y la globalización. Asimismo, mediante estas notas se procura avivar el interés sobre dichos temas. Con ese propósito, el artículo está formado por dos apartados: globalización y neoliberalismo.

\section{Globalización}

John Saxe-Fernández apunta que la globalización puede ser considerada de tres maneras: 1) como categoría científica, esto es "como un concepto cuyo referente histórico y empírico está centrado en el largo proceso multisecular de la internacionalización económica". ${ }^{4}$ 2) También puede comprenderse como una categoría histórica; en ese sentido, globalización es un equivalente de la internacionalización económica. Es, por tanto, un fenómeno que se da en el mundo y se caracteriza por los grandes y crecientes flujos de comercio, producción y de inversión entre los grandes consorcios y los países. Conforme a esta acepción, la globalización no es un fenómeno nuevo, sino, como escribe Carlos Vilas, es un proceso que abarca desde los siglos XIV y XV con el desarrollo del capitalismo mercantil y que ha tenido a lo largo de poco más de cinco siglos periodos de aceleración y desaceleración. ${ }^{5}$ 3) La globalización puede apreciarse desde el punto de vista de la sociología del conocimiento. Éste es su significado más extendido y se le presenta en la forma siguiente:

La globalización es un fenómeno nuevo, homogéneo y homogeneizante que conduce a la democracia, al progreso y al bienestar universal. El mercado global y su creciente expansión favorecen el desarrollo de las grandes empresas transnacionales y tienden a volver obsoletas las fronteras nacionales. También se dice que la globalización favorece el progreso y el bienestar universal; que la globalización

\footnotetext{
${ }^{4}$ John Saxe-Fernández, "Globalización e imperialismo", en John Saxe-Fernández (coord.) Globalización: crítica a un paradigma, México, Universidad Nacional Autónoma de México / Instituto de Investigaciones Económicas / Plaza y Janés editores, 1999 (3ª reimpresión, 2003), p. 9.

${ }_{5}^{5}$ Carlos Vilas, "Seis ideas falsas sobre globalización", en Globalización: crítica a un paradigma, op. cit., p. 73.
} 
económica impulsa la globalización democrática y que, por lo mismo, conduce a la desaparición progresiva del Estado o al menos a la pérdida de la importancia del mismo.

Esta versión, también conocida como versión "pop" de la globalización, es la más divulgada en los medios de comunicación masiva de los países de mayor nivel de desarrollo económico y es la que más aceptación ha tenido en los países de menor desarrollo relativo, especialmente entre los miembros de los grupos políticos en el poder. Pero ¿son realmente ciertos sus caracteres y alcances?, ¿nos encontramos en verdad cerca de lograr los beneficios que pregonan los partidarios de la globalización en esa concepción "pop"?

Como se ha dicho, la globalización es un largo proceso histórico que tiene su inicio con el mercantilismo que lleva a los pueblos de Europa Occidental, concretamente a los genoveses y venecianos, a buscar nuevas rutas para conseguir productos exóticos y colocar, a su vez, los bienes elaborados por ellos. Este proceso, en efecto, ha tenido momentos de gran aceleración con el avance de la ciencia y la tecnología y el desarrollo de mejores medios y sistemas de transporte, que permitieron la apertura de vías de acceso y la conquista de los mercados de Asia, África, América y Oceanía para dar lugar a la formación del mercado mundial y su creciente expansión.

Con la expansión mundial del comercio se favoreció, en segundo término, la globalización de la producción. La inversión de capitales y la adopción de nuevas tecnologías se extendió por distintas regiones del mundo y la producción de artículos sofisticados y de alto valor agregado permitió la multiplicación de la división del trabajo, al punto que se volvió práctica común y corriente la fragmentación del proceso productivo entre diferentes regiones y países. No obstante, resulta conveniente no perder de vista que nunca se ha dejado de lado la clasificación de país de origen, inclusive en las mercancías que tienen un grado escaso de elaboración.

La internacionalización de los mercados y de la producción demandó, y a su vez facilitó, en una tercera fase, la globalización financiera. Una primera escalada de este proceso ocurre a finales del siglo XIX y principios del siglo XX, lo que favorece la fusión del capital industrial con el capital financiero y con ella la transformación del capitalismo avanzado en imperialismo. En la actualidad, el desarrollo de los medios de comunicación y de la informática, así como de formas más eficientes de administración de los recursos de inversión han favorecido la preponderan- 
cia del capital financiero, cuyo manejo se ha vuelto cada vez más autónomo del capital industrial. A este proceso ha concurrido la desregulación casi universal de los mercados de dinero y de capitales, como lo apunta el profesor e investigador de la Facultad de Ciencias Políticas y Sociales de la UNAM Octavio Rodríguez Araujo. ${ }^{6}$

Cabe subrayar, sin embargo, que la globalización de la economía ha estado y está muy lejos de ser un proceso homogéneo. El desenvolvimiento de los diferentes países acusa marcadas desigualdades y dentro de cada país se tienen contrastes muy marcados en el grado de desarrollo que muestran las distintas regiones que lo configuran. También son apreciables los desajustes en el desarrollo que tienen las distintas actividades económicas y dentro de cada una de éstas la disparidad entre las unidades de producción de alto grado de capitalización y tecnología que dominan los grandes mercados frente a las unidades o empresas que acusan serias limitaciones de tipo técnico y financiero y que por lo mismo tienen una presencia débil en el mercado.

El carácter desigual de la globalización resulta evidente al tomar en cuenta el avance de la ingeniería genética, la automatización y robotización de ciertas fases del proceso productivo y el uso de las técnicas informáticas de punta, que son ya práctica común y corriente en los países de mayor desarrollo relativo, frente a los sistemas de producción y condiciones laborales provenientes del siglo XIX que se pueden apreciar en los países de menor grado de desarrollo o en determinadas regiones y actividades de países de desarrollo intermedio.

La afirmación que la globalización es homogeneizante tampoco se corrobora en la realidad. En verdad, la expansión mundial del capitalismo ha profundizado la diferenciación creciente entre países y regiones. La estadística internacional, como se puede apreciar en los anuarios del Banco Mundial, muestra que la distancia que separa el ingreso por habitante prevaleciente en los países más avanzados de aquellos que acusan un atraso relativo cada vez es mayor. Vilas apunta sobre esta cuestión: “[...] Si hay algo que se reproduce y acentúa, en escala mundial, es el desarrollo desigual y combinado de las relaciones y producciones materiales y culturales [...] la globalización nunca es un proceso histórico de homogeneización".?

\footnotetext{
"Octavio Rodríguez Araujo, "Política y neoliberalismo", en Globalización: crítica a un paradigma, op. cit., pp. 355 y 356.

${ }^{7}$ Carlos Vilas, "Seis ideas falsas sobre globalización", op. cit., p. 82.
} 
Conviene subrayar, además, que la globalización no ha sido capaz de beneficiar a todos los países y las diferencias existentes en los patrones de expansión permiten advertir que se ha entrado a una forma nueva de imperialismo. Este neoimperialismo lo identifica Rodríguez Araujo por los rasgos siguientes: ha sido precedido por una política de repercusiones económicas, sociales y culturales sin antecedentes históricos por su alcance, aplicación y casi uniformidad, el neoliberalismo; se trata de una política que casi no tiene oposición dentro de los países o en el plano regional; se basa en la exclusión de pueblos enteros que no son útiles a las empresas ni como productores ni como consumidores; además, se han desmantelado los mecanismos e instituciones de protección de la población mayoritaria, lo que indica un serio retroceso en esta materia hacia el siglo XIX.

Por lo que se refiere a las repercusiones de este neoimperialismo en la economía mundial, el mismo autor apunta, entre otras, que la tecnología expulsa o limita el empleo de trabajo humano en la producción de bienes y servicios; la globalización relativa permite desplazar parte o partes de la producción de las economías desarrolladas hacia los países que disponen de trabajo abundante y barato y este proceso se sigue hasta obtener los salarios más bajos, aunque ello impida el desarrollo de uno o de varios países; así, la economía mundial se ha vuelto una máquina muy poderosa, pero incontrolable.

Los países en vías de desarrollo, como son los latinoamericanos, han quedado al margen de los grandes beneficios que derivan del avance tecnológico y sólo se acude a ellos si cuentan con mano de obra barata y bien calificada que garantice niveles predeterminados de productividad y de competitividad. El mercado interno de este grupo de países, fuertemente debilitado por la distribución injusta del ingreso, no encierra interés para las grandes corporaciones de los países centrales: Estados Unidos, Japón, Inglaterra y Alemania, únicamente acuden a ellos para aprovechar su fuerza de trabajo, sus materias primas o bien por la necesidad de establecer factorías o plantas industriales que degradan la calidad del medio ambiente y que por esa misma razón ya no son aceptadas en su país de origen.

En opinión de Octavio Rodríguez Araujo, México también se ha quedado al margen de los beneficios de la globalización debido a estos elementos: “[...] su sector rural crecientemente depauperado, la tendencia a la quiebra de las empresas pequeñas y medianas, su economía informal en aumento y sin freno y las zonas 
indígenas". ${ }^{8}$ En este proceso de integración-desintegración, las políticas que siguen los estados nacionales se han subordinado al interés de las grandes empresas que hoy dominan la economía mundial. La acción de los gobiernos se ha limitado al propósito de que las grandes empresas no encuentren obstáculos. Dentro de este marco, la política de desarrollo que siguen los países dependientes está determinada, en buena medida, por el proyecto económico y los planes de las grandes potencias. Los propósitos de bienestar de la población y de justicia social se han dejado de lado.

No obstante que la globalización por su atractivo empaque tiende a manejarse como un modelo a seguir y en tal sentido sirve como justificante de las políticas contrarias a los intereses de las mayorías que se ponen en juego en los países en vías de desarrollo, lo cierto es que las naciones más poderosas, Estados Unidos, Japón, Inglaterra y Alemania buscan fortalecer su predominio en sus respectivas zonas de influencia económica. A este respecto, el propósito de los Estados Unidos de formalizar a la brevedad el Acuerdo de Libre Comercio de las Américas (ALCA) es un claro ejemplo; en tanto que en los países de menor desarrollo relativo, y México es uno de ellos, el gobierno "[...] actúa sobre la orientación, la estructura y el funcionamiento de la actividad económica y del sistema social para posibilitar y asegurar la exitosa operatividad del modelo de crecimiento dependiente". 9

La aseveración de que la globalización es la llave del progreso y del bienestar no es válida para muchos países. En las naciones de América Latina, como México, aumenta la pobreza, crece el desempleo y el subempleo y se ha degradado la calidad de la vida urbana. Esto es, con la globalización, la depauperación avanza y comprende, además de las clases populares, una porción creciente de la clase media. También se vuelven mayores las diferencias en la calidad del género de vida entre quienes pueden incorporarse al proceso de desarrollo y quienes permanecen marginados. Entre los factores que reflejan esas diferencias figuran: el cambio en la relación producto-empleo, hoy el producto nacional puede crecer aunque el empleo disminuya; la flexibilización laboral, que cada vez toca mayores segmentos de la población ocupada en la industria y los servicios; el deterioro del salario real;

8 Octavio Rodríguez Araujo, "Política y neoliberalismo", op. cit., p. 360.

${ }^{9}$ Marcos Kaplan, Formación del Estado Nacional en América Latina, Buenos Aires, Amorrortu editores, 1969, p. 219, citado por Saxe-Fernández, John, "Globalización e imperialismo", op. cit., p. 14. 
y el crecimiento más acelerado de los grupos de población que viven en condiciones de pobreza respecto a la tasa nacional de aumento demográfico.

El principio de que la globalización económica favorece la globalización de la democracia resulta ser también falso. En la definición de la democracia, como participación en la lucha electoral, estamos frente a un régimen de inclusión. Pero la pobreza y la marginación social es, por lo contrario, un régimen de exclusión. Según Carlos Vilas, la democracia condiciona en el individuo estos sentimientos: igualdad, autonomía, responsabilidad y eficacia, sin embargo, la pobreza persistente tiende a negarlos. ${ }^{10}$ En esas condiciones, el ejercicio de la democracia se reduce a la lucha electoral y al discurso político, mas no trasciende y engloba a los sectores mayoritarios de la población que en buena medida militan en las filas del abstencionismo.

La propuesta acerca de que la globalización acarrea la desaparición progresiva del Estado o cuando menos genera una pérdida de la importancia del mismo tampoco se observa en la realidad. Actualmente, se aprecia un fortalecimiento muy marcado del nacionalismo en los países de mayor desarrollo relativo y se acrecienta la diferenciación respecto al país de origen, sobre todo en materia de empleo, desde la incorporación o no del sujeto demandante, su remuneración y sus prestaciones. Estos elementos explican una parte del aumento registrado en los beneficios empresariales al nivel de toda la economía y, por tanto, para apoyar las diferencias en el trato laboral debe intervenir el gobierno. Así, los recursos políticos y militares de cada Estado juegan un papel estratégico para mantener y acrecentar los espacios económicos y comerciales que demanda la globalización.

El fortalecimiento del nacionalismo va ligado muy de cerca con la importancia creciente del regionalismo, esto es con la mayor importancia que cobran los bloques económicos o zonas de influencia. Pablo González Casanova explica que la globalización puede llegar a entenderse de una manera engañosa si no se le vincula con los procesos de dominación y apropiación. ${ }^{11}$ Desde esta óptica puede advertirse cómo los gobiernos de los países avanzados no dejan de intervenir en el desarrollo económico y cómo esa intervención adquiere formas cada vez más sofisticadas.

${ }^{10}$ Carlos Vilas, "Seis ideas falsas sobre globalización", op. cit., pp. 87-89.

11 Pablo González Casanova, "Los indios de México hacia el nuevo milenio", en La Jornada, México, septiembre 1998, p. 12. 
De este modo, si bien es cierto que día con día es mayor el número de países y de empresas que concurren al mercado mundial, también se puede apreciar que esa expansión va acompañada por una creciente concentración del poder económico en las potencias mundiales que someten mediante políticas de Estado a las grandes corporaciones transnacionales, al flujo del comercio y también a la intermediación financiera.

Sin duda con la globalización cambia la forma de organización y el funcionamiento del gobierno, pero ese proceso de cambio ha tendido a fortalecer al Estado. Esta tendencia se acrecienta con las relaciones cada vez más frecuentes y estrechas que se dan entre las corporaciones multinacionales y los gobiernos de los países donde radican sus firmas matrices. De ahí el avance de la tecnología con un sentido altamente nacionalista en lugar del desarrollo de una tecnología realmente "globalizada".

La concentración de las grandes corporaciones en un número reducido de países puede apreciarse cuando se considera que a principios de la última década del siglo anterior operaban en el mundo 37 mil empresas multinacionales, mismas que contaban con 170 mil firmas subsidiarias. De ese universo, el 70\% del total operaba sobre una base nacional que las regulaba, penalizaba, protegía o subsidiaba nacional e internacionalmente. El mismo 70\% de grandes empresas se localizaba sólo en los 14 países más desarrollados de la Organización para la Cooperación y el Desarrollo Económico (OCDE) y el 90\% de las firmas matrices se ubicaba también en los países de mayor desarrollo relativo. ${ }^{12}$

El poder de las firmas transnacionales ha crecido de manera considerable, pero la concentración de sus oficinas matrices en un país determinado explica el mantenimiento del dominio de los países más avanzados en sus respectivas zonas de influencia: Estados Unidos en América Latina; Alemania y Gran Bretaña en Europa; Japón en el Sureste de Asia, donde todavía es preponderante la participación norteamericana; mientras que en África y el Medio Oriente la influencia dominante corresponde a Europa Occidental.

La economía mundial, a pesar de sus grandes avances, acusa el predominio de tres grandes potencias: Alemania y Japón, que han tenido un marcado ascenso

\footnotetext{
12 John Saxe-Fernández, "Globalización e imperialismo", op. cit., p. 32.
} 
desde el final de la Segunda Guerra Mundial, no obstante sus fases cortas de atonía; y los Estados Unidos, que si bien ha experimentado una ligera pérdida de su poder en materia económica, se mantiene todavía como líder en el plano económico y, desde luego, en asuntos militares. Andrew Glyn y Bob Sutcliffe estiman que la carencia de un líder claramente reconocido e identificado podría favorecer "un nivel de conflicto entre las principales potencias mayor que durante los 50 años previos". ${ }^{13}$ Por otra parte, Christopher Chase-Dunn y Bruce Podbnik examinan los factores que, en su opinión, evitarían otro conflicto mundial, mismos que son: la existencia de armas de destrucción masiva cuyo empleo llevaría posiblemente al fin de la especie humana; la consolidación gradual de instituciones internacionales con capacidad para coordinar un mundo multipolar; y la internacionalización de la burguesía, que procura evitar quebrantos en sus intereses comunes.

Por otra parte, Chase-Dunn y Podbnik consideran también cuatro factores que podrían impulsar una conflagración mundial: el fin del ciclo de ascenso económico de onda larga, también conocido como ciclo Kondratiev A, que terminará hacia el año 2025; la declinación hegemónica de los Estados Unidos; la presión poblacional sobre los recursos naturales y la desigualdad global. Aunque existen medidas que posiblemente frenarían o impedirían un conflicto de esa naturaleza, tales como la destrucción del armamento, la interdependencia internacional, la integración política y el desarme. Dichos investigadores concluyen que el riesgo de que ocurra un conflicto mundial será mayor hacia los años 2020 y la probabilidad de su realización la estiman en un $50 \%$, proporción que con toda razón les parece a los analistas antes mencionados muy elevada. ${ }^{14}$

\section{Neoliberalismo}

La globalización, en esta fase del neoimperialismo, ha dado lugar, entre otros, a cuatro grandes procesos: 1. La supervolatilidad que parece autónoma de grandes masas de capital financiero; 2 . La fragmentación y dispersión alrededor del mundo de las diversas fases de los procesos de producción, incluyendo servicios; 3 . La integración progresiva de los mercados nacionales al mercado mundial como resultado de patrones de consumo más homogéneos; y 4. El cambio de varios aspec-

\footnotetext{
${ }^{13}$ Andrew Glyn y Bob Sutcliffe, "El nuevo orden capitalista global pero sin liderazgo", en Globalización: crítica a un paradigma, op. cit., p. 130.

${ }^{14}$ Christopher Chase-Dunn y Bruce Podbnik, "La próxima guerra mundial: ciclos y tendencias del sistema mundial”, en Globalización: crítica a un paradigma, pp. 153 y 154.
} 
tos de la existencia social en razón del avance ocurrido principalmente en materia de comunicaciones e informática. Cabe advertir, sin embargo, que no todos los habitantes del mundo han recibido los beneficios de estos avances. Por lo mismo, los países centrales convinieron en la definición de una política económica, que según sus expertos y líderes sería capaz de permitir al resto de las naciones del mundo la obtención de dichos beneficios: el neoliberalismo, política que se ha tratado de imponer en los países periféricos o subdesarrollados desde el Consenso de Washington.

Larry S. Carney, autor del ensayo titulado "Globalización: ¿el legado final del socialismo?", presenta una referencia sobre el contenido de la política neoliberal en la forma siguiente:

- La eliminación de abultados déficit fiscales, especialmente mediante la reducción del gasto público.

- La reorientación del gasto público a favor de los sectores educativo y de salud y quizás de la infraestructura.

- El establecimiento de una amplia base tributaria con tasas modestas.

- La determinación de tasas de interés por mecanismos de mercado, preferentemente positivas, pero a un nivel moderado.

- El mantenimiento de un tipo de cambio competitivo capaz de promover las exportaciones y de lograr balanzas financiables en la cuenta corriente.

- La promoción de las exportaciones, especialmente de productos no tradicionales, y la liberalización de las importaciones.

- El fomento de la inversión extranjera directa que proporcione capital, calificación laboral y tecnología.

- La venta de empresas públicas para abatir el nivel de los subsidios y porque se considera que la empresa privada es más eficiente.

- La desregulación para aumentar la competencia y facilitar la incursión del sector privado en la actividad económica; $\mathrm{y}$ 
- La garantía sobre los derechos de propiedad con objeto de estimular la inversión nacional y extranjera. ${ }^{15}$

James Petras y Morris Morley examinaron la trayectoria del neoliberalismo en América Latina. Ellos parten de la consideración de que el descontento de los pueblos no se manifiesta en las urnas electorales, pero cuando ocurre se aprecia que el político triunfador como un enemigo de las recetas neoliberales, cuando llega al poder, sigue y aplica medidas de ese mismo corte. En consecuencia, ellos procuran en su trabajo vislumbrar alguna alternativa a este ciclo político recurrente.

Asimismo, esos autores apuntan que los regímenes neoliberales han tenido en América Latina tres momentos muy marcados: ascenso, desde principios de los años ochenta del siglo XX; decadencia, al final de ese mismo decenio; y reproducción, que arranca en los últimos cinco años del siglo anterior. Los gobiernos de los países de América Latina han apoyado su política económica en los programas de estabilización y ajuste diseñados por los técnicos del Fondo Monetario Internacional y del Banco Mundial, mismos que también siguen los postulados del Consenso de Washington. ${ }^{16}$

Así, en la primera etapa, que corresponde en México a la administración de Miguel de la Madrid, se procuró el ajuste del gasto público y la estabilización de los precios. Además, se inició el ajuste estructural consistente en el desmantelamiento del sector público y la consiguiente privatización de empresas y organismos. El gobierno dio prelación al pago de la deuda pública externa e interna con recursos que se hubieran podido canalizar a la inversión productiva o bien a la atención de grandes carencias sociales. A pesar de la instrumentación de las medidas recomendadas y en contra de los resultados que esperaban las instituciones internacionales y el gobierno de México se fracasó en el objetivo de activar el desarrollo económico y conseguir una distribución más equitativa del ingreso. Lejos de reconocer las deficiencias de la política recomendada, los técnicos de Banco Mundial y del Fondo Monetario Internacional adujeron que las medidas de ajuste no habían sido aplicadas de manera enérgica, consistente y sostenida.

\footnotetext{
${ }^{15}$ Larry S. Carney, “Globalización:¿el legado final del socialismo?”, en Globalización: crítica a una paradigma, op. cit., pp. 174 y 175.

16 James Petras y Morris Morley, "Los ciclos políticos neoliberales: América Latina se ajusta a la pobreza y a la riqueza en la era de los mercados libres", en Globalización: crítica a un paradigma, op. cit., p. 216.
} 
En la segunda fase, los candidatos a la presidencia de los países latinoamericanos, Carlos Salinas de Gortari en el caso de México, ofrecieron durante sus campañas electorales luchar contra la pobreza. Sobre este particular se anuncia en México el programa de solidaridad, superar el estancamiento económico y terminar con la fuga de capitales. Sin embargo, una vez conseguido el poder, se adoptaron con mayor fuerza las medidas contenidas en la agenda neoliberal. Es más, los nuevos presidentes latinoamericanos declararon que la aplicación de este tipo de política sería radical.

Durante los primeros años de sus respectivos gobiernos, la economía latinoamericana tendió a mejorar. Pero a partir del tercero o del cuarto año aumentó fuertemente el desempleo abierto y disfrazado y la economía volvió a frenarse. La aplicación de medidas deflacionarias, los préstamos de las instituciones internacionales y los ingresos de capital especulativo contribuyeron a frenar la inflación durante el corto plazo, mas poco después, al cesar el ingreso del capital especulativo y restringirse el apoyo financiero proveniente del exterior, los principales países latinoamericanos registraron crisis estructurales. Cabe recordar la caída de la economía mexicana iniciada en diciembre de 1994, que se transformó en el llamado "efecto tequila" y lesionó también el avance económico de Brasil y Argentina.

La tercera etapa del neoliberalismo se inició a mediados de los años noventa. No obstante que una vez más se recurrió al discurso populista, por ejemplo en el caso de México la campaña de Ernesto Zedillo Ponce de León prometió "el bienestar de la familia", los candidatos enfatizaron que las políticas de ajuste estructural no serían pasajeras. Se pedía un sacrificio temporal a cambio de alcanzar beneficios duraderos en el largo plazo.

Al llegar al ejercicio del poder, los nuevos presidentes de América Latina pusieron en marcha medidas de política económica que siguieron erosionando los patrones de vida de los sectores populares y de la clase media baja. Algunos investigadores, intelectuales y analistas advirtieron, en su oportunidad, que las políticas de corte neoliberal no propiciarían el desarrollo social ni la superación de los problemas económicos, pero que sí favorecían una espiral ascendente en los beneficios, ganancias, intereses, utilidades y rentas, lo que acrecentaba la porción del ingreso nacional captado por el sector privilegiado de la población, mientras que los trabajadores recibían una proporción cada vez menor. Esta tendencia polarizó el tejido social y gradualmente se destruyeron muchas de las ilusiones que había generado el neoliberalismo. 
En México, esta tercera oleada de neoliberalismo tampoco mejoró las condiciones socioeconómicas de la población. El nuevo y más estricto programa de austeridad incluyó recortes severos en el gasto público y en la inversión. Adicionalmente, se impulsaron reajustes en las dependencias del gobierno y en los organismos y empresas de la administración pública. Los precios y tarifas de los energéticos se incrementaron de manera considerable y también se elevaron los precios de los alimentos, así como la tasa del impuesto al valor agregado. Esas medidas, junto con la devaluación de la moneda, empobrecieron a los sectores más amplios de la clase media y desde luego a los grupos de menores ingresos.

A pesar del fracaso de la política neoliberal, que llevó a los pueblos de América Latina a expresar de manera más abierta su descontento - como lo refleja el mayor número de movilizaciones y la aplicación más estricta de acciones represivas - en la siguiente oportunidad, al inicio del siglo XXI, los candidatos partidarios del neoliberalismo volvieron a disfrazarse de populistas y prometieron una vez más cambios en la política económica. En México, Vicente Fox prometió un vehículo popular, un "vocho", y una pequeña empresa, un "changarro", a cada familia. Sin embargo, al resultar electo - en buena medida como efecto del rechazo de la mayoría de la población a la línea política neoliberal seguida por las tres administraciones precedentes - el Presidente Fox aceptó llevar más lejos las medidas del cambio estructural propuestas por los funcionarios del Fondo Monetario Internacional y del Banco Mundial.

A tres años de gobierno, los resultados no son alentadores. La economía prácticamente ha permanecido estancada, el desempleo ha crecido, lo mismo que la llamada economía informal, que sirve como una válvula de escape a la amenaza de miseria, la emigración incontenible de trabajadores de la ciudad y del campo que no encuentra ocupación dentro del país, emigración que además de aliviar la presión política se ha transformado por su abultado crecimiento en una importante fuente de divisas que alivia la pobreza en que viven los familiares de los emigrantes que sí permanecen en el país, la amenaza de abolir los principios jurídicos que defienden los derechos de los trabajadores, la presión para disminuir la calidad de los servicios y las prestaciones que ofrecen las instituciones de seguridad social, así como la tendencia descendente del salario real.

Por otra parte, escriben Petras y Morley: “(la) liberación de los flujos financieros no ha contribuido a nuevas inversiones de capitales a gran escala en las actividades productivas de largo plazo. La mayoría de los nuevos flujos financieros ha sido 
dirigida a obligaciones de corto plazo de alto interés y a bonos gubernamentales con el fin de reforzar las reservas extranjeras, cumplir con los pagos de la deuda o equilibrar las cuentas con el exterior". ${ }^{17}$

Los mismos autores sostienen que la política neoliberal tiene muy poco que ver con la necesidad de impulsar un desarrollo económico y social sostenido y cada vez más equitativo. En efecto, la privatización de empresas del sector público no añade capacidad productiva ni genera nuevas fuentes de empleo, y cuando se ha traducido en nuevas inversiones ha tenido como contrapartidas la mayor importación de bienes intermedios y de materias primas o bien el aumento en la remesa de utilidades al exterior, fenómenos que desalientan la capitalización en otras ramas productivas y presionan al crecimiento de las compras en el exterior.

La liberación del comercio, a su vez, ha propiciado el quebranto de millares de pequeñas y medianas empresas en toda América Latina y, a la vez, ha fortalecido el dominio del mercado interno por las grandes corporaciones transnacionales que basan parte de su estrategia de operación en las importaciones crecientes de bienes de consumo, bienes de consumo intermedio y de capital lo que refuerza la dependencia del exterior. Por lo mismo, el principio neoliberal que sostiene que la apertura comercial impulsa a las empresas a modernizar su tecnología, elevar la calidad de la fuerza de trabajo, abrir nuevos mercados al exterior en un breve tiempo y en el contexto mundial, no resulta válido cuando se aplica a países y empresas que no se encuentran al mismo nivel de desarrollo.

En esta fase del neoliberalismo, sin duda, ha aumentado la presión de los países centrales y de los organismos mundiales para que los países dependientes, en vías de desarrollo o periféricos eliminen las restricciones que mantienen en áreas estratégicas (energéticos, minería, agricultura, recursos forestales y pesqueros). Con ello se pretende alentar la concurrencia del capital extranjero y su inversión en procesos productivos de actividades importantes. En el caso de los países de América Latina, aceptar esas exigencias neoimperialistas significaría condenarse a incrementar la exportación de energéticos y materias primas que son indispensables para garantizar la expansión futura de sus economías nacionales. Es más, buena parte de sus recursos no renovables se perderían para siempre.

17 Idem, p. 242 
La declinación o el estancamiento del mercado interno, la quiebra de pequeñas y medianas empresas industriales, la crisis del sector agropecuario, la dependencia creciente de los bienes importados y los altos costos del capital favorecen la penuria fiscal que busca remediarse con financiamientos o con inversiones directas provenientes del exterior. Esto último condiciona la aceptación de los gobiernos de América Latina, y México no es la excepción, a las medidas o reformas de ajuste estructural. Y el ciclo tiende a repetirse.

La salida de este ciclo no es fácil, toda vez que como apuntan Petras y Morley "(los) actores clave - internacionales y nacionales, productivos y financierosbasan sus decisiones de inversión en la perpetuación del modelo neoliberal". ${ }^{18}$ Por ello, si un personaje de la política promete cambiar las reglas del juego y llega al poder, cuando intenta cumplir ese compromiso de inmediato es amenazado con la fuga de capitales o con la reducción drástica de la inversión privada. Ahora bien, los políticos que se expresan abiertamente por un modelo alternativo de desarrollo son tachados por los representantes y los partidarios del neoliberalismo, así como por los medios a su servicio, televisión, radio y prensa, de "populistas" o "reformistas" y mediante costosas y persistentes campañas se busca debilitar sus posibilidades de que puedan llegar al poder. Cuando estas acciones no parecen o no resultan efectivas se recurre a medidas más directas.

En consecuencia, la única posibilidad de un cambio real se encuentra, según Petras y Morley, en nuevos movimientos sociopolíticos.

\section{Conclusiones}

1. Globalización y neoliberalismo no son sinónimos. La globalización puede identificarse con la fase más reciente del capitalismo y el neoliberalismo con la política económica que los países avanzados procuran imponer en todo el mundo por ser la más conveniente a sus intereses políticos y, desde luego, económicos.

2. En la etapa actual, caracterizada por la existencia de grandes empresas transnacionales y la globalización de los mercados de dinero y capitales, se considera que las relaciones económicas entre países con niveles muy diferentes de desarrollo refuerzan y renuevan los lazos de dominación y dependencia.

${ }^{18}$ Ibid, p.238. 
De ser así, esta fase de la globalización bien podría denominarse neoimperialismo, como lo sugiere Octavio Rodríguez Araujo.

3. Las dificultades que enfrentan los países periféricos para crecer más aprisa y lograr una distribución más justa de su renta nacional muestran objetivamente que la globalización está muy lejos de tener las virtudes que se le atribuyen en los análisis "pop”.

4. El desarrollo desigual entre países, regiones y sectores es característico del sistema capitalista. En su fase neoimperialista, la aplicación de una política económica homogénea, el neoliberalismo, en países que tienen distinto nivel de progreso material, social y cultural, así como una muy diferente dotación de recursos naturales, tecnológicos y de capital, agudiza la brecha que separa a los países centrales de los periféricos y tiende a agravar la pobreza y marginación que padecen dos terceras partes de la población mundial.

5. El predominio de los países de mayor desarrollo relativo, Estados Unidos, Japón, Alemania y Gran Bretaña, y la presencia cada día más significativa de las grandes empresas transnacionales, han impulsado el establecimiento de sistemas democráticos de gobierno en los países subdesarrollados, pero sólo en sus manifestaciones formales. A su vez, las naciones más avanzadas favorecen la permanencia y continuidad de esta democracia formal en los países periféricos, en tanto les garantice el cumplimiento en el pago de las obligaciones financieras, les facilite la operación rentable y segura de sus empresas y les permita la explotación de los recursos naturales, así como la contratación de la fuerza de trabajo con salarios bajos y de ser posible sin prestaciones.

6. La vinculación de intereses entre los gobiernos y las empresas transnacionales de los países más avanzados con el gobierno y los sectores privilegiados de los países periféricos alienta la formación de oligarquías, lo que tiende a reforzar la influencia de los factores que frenan y distorsionan el avance de la economía, pero que, al mismo tiempo, estimula el desempleo, el crecimiento de la economía informal y la pobreza. Estas fuerzas negativas tienden a reproducirse y agravarse en cada nuevo ciclo político.

7. La solución a los problemas económicos que provoca el neoimperialismo y que agrava la aplicación de la política neoliberal en los países de menor desarrollo relativo, como es el caso de México, no se encuentra en el terreno económico sino en el campo de la política. 